\title{
Right-sided endocarditis caused by polyclonal Staphylococcus aureus infection
}

\author{
Yotam Kolben ${ }^{4 *}$, Y Yuval Ishay ${ }^{1}$, Henny Azmanov ${ }^{1}$, Assaf Rokney², Moti Baum², Sharon Amit ${ }^{3}$ and Ran Nir-Paz ${ }^{3}$
}

\begin{abstract}
We present a case of bacterial endocarditis with both methicillin-sensitive and methicillin-resistant Staphylococcus aureus, which based on typing, originated from two distinct clones. Such a case may be misinterpreted by microbiology lab automation to be a monoclonal multi-drug resistant Staphylococcus aureus, while simple microbiology techniques will instantly reveal distinct clonality.
\end{abstract}

Keywords: Staphylococcus aureus, Polyclonal infection, Endocarditis

\section{Background}

Bloodstream infection with Staphylococcus aureus (S. aureus) is a common occurrence in admitted patients. Such bacteremic events may represent one of many clinical scenarios from line infection, skin and soft tissue up to osteomyelitis or endocarditis, and may vary according to patients' age $[1,2]$. Several scoring systems were developed to identify patients with life-threatening infective endocarditis better [3]. Nevertheless, polymicrobial infections in the setting of $S$. aureus bacteremia are a less common occurrence, and infection with two subtypes/morphotypes of the same bacteria is considered an uncommon event [4]. Obviously, in the event of such multi-morphotype infections, a complicated and unanticipated clinical course could follow, resulting in a delayed antibiotic response. Thus, the importance of such an event is underlined by the prevalence of automated and molecular methods for the characterization of bacterial isolates, which may-in certain cases-fail to detect such occurrences.

*Correspondence: yotamkol@hadassah.org.il

${ }^{4}$ Department of Medicine, Hadassah Medical Organization and Faculty of Medicine, Hebrew University of Jerusalem, Jerusalem, Israel

Full list of author information is available at the end of the article

\section{Case presentation}

A 37-year-old homeless patient was admitted after being found lying in the street, weak but fully conscious. On arrival, the patient did not have any localizing symptoms but admitted to using intravenous (IV) heroin the same evening. One month prior to his current admission, he was observed for a small abscess in his right arm for which he refused percutaneous draining. The patient's previous medical history includes untreated schizophrenia and glucose-6-phosphate dehydrogenase deficiency. During his current presentation, his vital signs were within normal limits and his physical examination was unremarkable except for a small abscess in his right arm. His blood tests were significant for a slightly elevated white blood cell count of $12.3 \times 10^{9} / \mathrm{L}$ with a relative neutrophilia of $83.5 \%$, hemoglobin 11.1 gr\%, sodium $125 \mathrm{mmol} / \mathrm{L}$ and an elevated C-reactive protein (CRP) of $13.7 \mathrm{mg} / \mathrm{dl}$. The rest of his blood tests, including ethanol, were normal. Urine toxicology was positive for cannabinoids and morphine. His chest X-ray was unremarkable, and electrocardiogram showed sinus tachycardia with no other abnormalities. On further exam, this finding on his right arm was determined to be an area of induration and cellulitis with no abscess. Early after his admission, he started suffering from a high fever, up to $40{ }^{\circ} \mathrm{C}$. Blood cultures were obtained and antibiotic treatment with IV cefazolin $1000 \mathrm{mg}$ three times daily (tid) was initiated. original author(s) and the source, provide a link to the Creative Commons licence, and indicate if changes were made. The images or other third party material in this article are included in the article's Creative Commons licence, unless indicated otherwise in a credit line to the material. If material is not included in the article's Creative Commons licence and your intended use is not permitted by statutory regulation or exceeds the permitted use, you will need to obtain permission directly from the copyright holder. To view a copy of this licence, visit http://creativecommons.org/licenses/by/4.0/. 
Concurrently, a new systolic murmur in the left sternal border was noted. His blood cultures were positive for methicillin-resistant Staphylococcus aureus (MRSA) with resistances profile that included clindamycin, erythromycin and methicillin. Treatment was changed accordingly to IV vancomycin $1000 \mathrm{mg}$ twice daily (bid). The following day, another blood culture also came back positive for MRSA but with a difference in the resistances profile which now included chloramphenicol and methicillin. After 2 days, an additional blood culture came positive, but this time with methicillin-sensitive Staphylococcus aureus (MSSA), with resistances to clindamycin and erythromycin (Table 1).

This raised the question of a possible lab misinterpretation or a rare case of infection with two distinct $S$. aureus clones simultaneously. The lab was notified of the two possibilities and to our surprise, microbiological lab analysis revealed two distinct $S$. aureus isolates (Fig. 1). Further analysis at the S. aureus national reference center confirmed the presence of $m e c A$ in the MRSA isolate. In addition, the isolate was Panton-Valentine Leukocidin ( $p v l$ ) positive, spa type t121 (repeat succession 11-19-21-17-34-24-34-22-25), and SCCmec type IV. The MSSA isolate was found to be mecA and pvl negative, and spa type t6605 (repeat succession 08-16-02-25-02-02-25-34-25).

Due to multiple positive blood cultures with both MSSA and MRSA, a new murmur, and a history of IV drug use, infective endocarditis was suspected. Rheumatoid factor and complement levels were within normal limits. Trans-thoracic echocardiography showed an echogenic mass of $10 \times 7 \mathrm{~mm}$ on the tricuspid valve, attached to the septal leaflet, with at least moderate tricuspid regurgitation. Trans-esophageal echocardiography confirmed the previous findings and showed flail prolapse of the septal leaflet with a ruptured chordae tendineae and a severe, very eccentric jet of tricuspid regurgitation. According to the modified Duke criteria [5], a diagnosis of right-sided endocarditis was confirmed, with two major (persistent $S$. aureus bacteremia, vegetation) and two minor (IV drug use as predisposition, fever) criteria.

After the initiation of vancomycin antibiotic therapy, the MRSA stopped growing from the blood cultures within 2 days, while MSSA cultures were still positive for additional three more days. The subsequent blood

Table 1 Antibiogram showing differences in blood cultures

\begin{tabular}{|c|c|c|c|c|c|c|c|c|c|c|c|c|}
\hline Culture time & Organism & Chlora & Clinda & Tri-sul & Doxy & Eryth & Genta & Mino & Mupi & Oxa/methi & Rifa & Vanco \\
\hline Day 1 & S. aureus & & R & S & & $\mathrm{R}$ & S & S & S & R & S & S \\
\hline Day 2 & S. aureus & R & S & S & & S & S & S & S & R & S & $\mathrm{S}$ \\
\hline Day 4 & S. aureus & & $\mathrm{R}$ & S & S & $\mathrm{R}$ & & & & S & S & \\
\hline
\end{tabular}

Breakpoints in lab are determined according to CLSI criteria

Chlora chloramphenicol; Clinda clindamycin; Tri-sul trimethoprim-sulfamethoxazole; Doxy doxycycline; Eryth erythromycin; Genta gentamycin; Mino minocycline; Mupi mupirocin; Oxa/methi oxacillin/methicillin; Rifa rifampicin; Vanco vancomycin

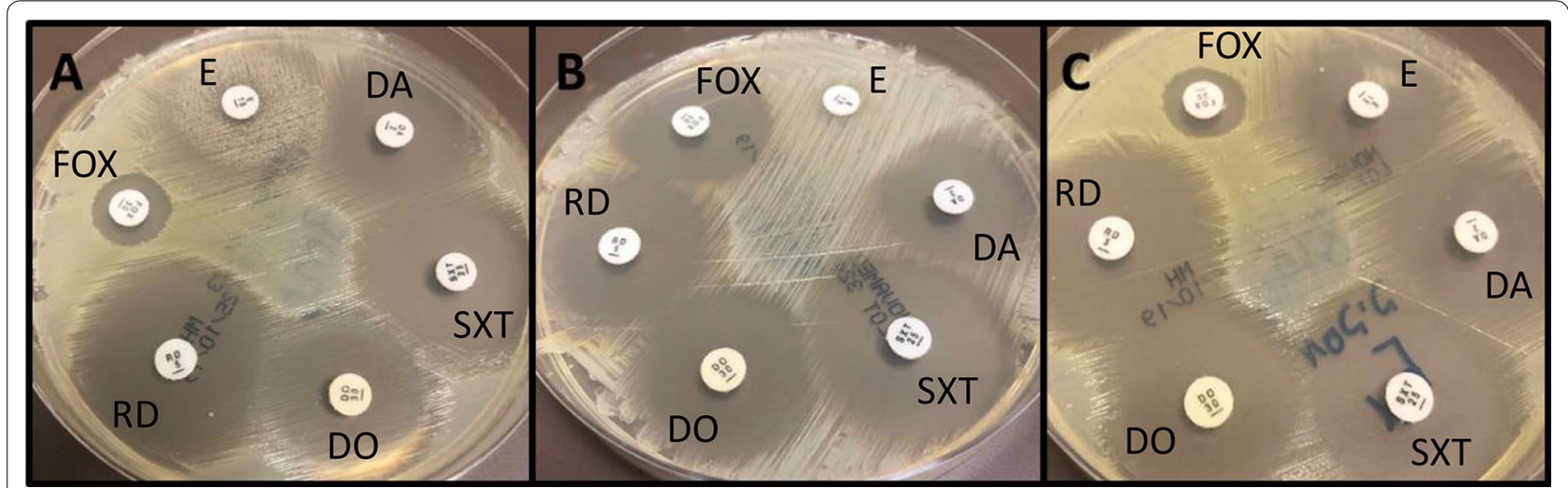

Fig. 1 Two Staphylococcus aureus morphotypes isolated from a single blood culture. Muller-Hinton agar petri dishes with antimicrobial disks (E-erythromycin, DA-clindamycin, SXT-trimethoprim/sulfamethoxazole, DO-doxycycline, RD-rifampicin, FOX-cefoxitin) depicting the two morphotypes. A Mixed culture - two distinct zones are noted around the erythromycin disk. B Methicillin-sensitive Staphylococcus aureus (FOX sensitive) with inducible clindamycin resistance (positive "D-test"). C Methicillin-resistant (FOX resistant) Staphylococcus aureus sensitive to all other antimicrobials 
cultures were negative. The patient completed 1 month of treatment with IV vancomycin. He continued treatment with trimethoprim-sulfamethoxazole $800 / 160 \mathrm{mg}$ bid and ciprofloxacin $500 \mathrm{mg}$ bid orally for another week and was discharged in general good health. The patient returned to the emergency department 6 and 7 months after discharge for various non-cardiac and non-infectious complaints. Three sets of blood cultures that were obtained on those presentations were sterile.

\section{Materials and methods}

Multiplex real time polymerase chain reaction for the simultaneous detection of $m e c A, m e c C, p v l$ and $n u c$ gene, which serve as an internal amplification control, was performed as described previously [6, 7]. With the exception of mecA primers and probe sequences which used the CDC TaqMan probes for mecA [8]

Molecular typing of the isolate by spa typing and SCCmec typing was performed as described previously [9]. The spa typing analysis was performed using BioNumerics 7.6.3 software.

\section{Discussion}

Staphylococcus aureus bacteremia was initially described over a century ago [10]. It is a lethal pathogen with high morbidity and mortality rates; $10-30 \%$ of patients diagnosed with $S$. aureus bacteremia will die [11]. The emergence of drug-resistant strains, such as MRSA, particularly community acquired-MRSA strains, exacerbate the phenomenon. In this case, our patient's MRSA strain was of the t121 clone. This strain is more common in Africa, Asia and Europe, and accounts for $5 \%$ of MRSA isolates in these regions. Nevertheless, only $10 \%$ of t121 clones are methicillin resistant [12]. The patient's MSSA strain was of spa type t6605, a subtype of ST398. ST398 was found to be both hospital and community acquired. It is presumed to be of livestock origin, and it shows almost universal erythromycin and clindamycin resistance [13], as in our case. While coagulase-negative staphylococci are known contaminants of blood cultures and polyclonal bacteremia was previously described $[14,15]$, analysis of cultures of S. aureus do not typically show polyclonal bacteremia. In one study, molecular analysis of the first blood cultures taken from 41 patients with $S$. aureus bacteremia and 21 bacteremia-associated catheter tip isolates revealed monoclonality in $100 \%$ of the cases. Nevertheless, rare cases of polyclonal S. aureus bacteremia were previously described. In an analysis of 122 MRSA isolates from a neonatal intensive care unit, two cases showed two genetically unrelated strains which were isolated from a single episode of MRSA infection
[16]. Recently, a case of a 36-year-old woman with a history of IV drug abuse, suffering from endocarditis with isolation of two MSSA strains was described [4]. Similarly, our patient was an IV drug user and presented with a high fever. Considering these reports, it is not surprising that multiple strains of $S$. aureus were isolated in nasal carriers [17]. A mathematical model predicted that about $6.6 \%$ of $S$. aureus carriers host more than one strain [18].

To our knowledge, this is the first description of concurrent isolation of different molecular types of both MSSA and MRSA in a single episode of bacteremia. Although it was never described before, maybe it was just overlooked in most cases. It was previously argued that physicians have a cognitive bias regarding the diagnosis of infective endocarditis [19], and it may be one of the causes for the rarity of the diagnosis of polymicrobial endovascular infections. This case emphasizes that even though automated blood cultures in the microbiology lab have many advantages, in a case of an infection with different strains of the same species, there may be false negative results. The use of agar plates is still highly valuable in these cases. A high index of suspicion led to the diagnosis in this case, but there is a possibility that in some cases we miss the whole picture due to automation. High-risk populations such as IV drug users should always raise concern for polymicrobial infection, and clinicians must be alert.

\section{Abbreviations}

IV: Intravenous; MRSA: Methicillin-resistant Staphylococcus aureus; MSSA: Methicillin-sensitive Staphylococcus aureus; pvl: Panton-Valentine Leukocidin; S. aureus: Staphylococcus aureus.

\section{Acknowledgements \\ Not applicable.}

\section{Authors' contributions}

$Y K, Y I, H A$ and RNP analyzed and interpreted the patient data and were major contributors to writing the manuscript. AR, MB and SA analyzed the data and were contributors to writing the manuscript. All authors read and approved the final manuscript.

\section{Funding}

No funding was obtained for this paper.

Availability of data and materials

All data generated or analyzed during this study are included in this published article.

\section{Declarations}

Ethics approval and consent to participate

We declare that this case report was performed in accordance with the Declaration of Helsinki and the local ethics committee of Helsinki at Hadassah Ein Kerem, Jerusalem.

Consent for publication

The patient gave his consent to publish this data. 


\section{Competing interests}

All authors declare no financial and personal relationships with other people or organizations that could inappropriately influence (bias) their work.

\section{Author details}

${ }^{1}$ Department of Medicine, Hadassah Medical Organization and Faculty of Medicine, Hebrew University of Jerusalem, Jerusalem, Israel. ${ }^{2}$ Government Central Laboratories, Ministry of Health, Jerusalem, Israel. ${ }^{3}$ Department of Microbiology, Hadassah Medical Organization and Faculty of Medicine, Hebrew University of Jerusalem, Jerusalem, Israel. ${ }^{4}$ Department of Medicine, Hadassah Medical Organization and Faculty of Medicine, Hebrew University of Jerusalem, Jerusalem, Israel.

Received: 17 May 2021 Accepted: 6 July 2021

Published online: 11 August 2021

\section{References}

1. Campbell AJ, Al Yazidi LS, Phuong LK, et al. Pediatric Staphylococcus aureus bacteremia: clinical spectrum and predictors of poor outcome. Clin Infect Dis. 2021. https://doi.org/10.1093/cid/ciab510.

2. Rose W, Fantl M, Geriak M, Nizet V, Sakoulas G. Current paradigms of combination therapy in methicillin-resistant Staphylococcus aureus (MRSA) bacteremia: does it work, which combination and for which patients? Clin Infect Dis. 2021. https://doi.org/10.1093/cid/ciab452.

3. Palraj BR, Baddour LM, Hess EP, et al. Predicting risk of endocarditis using a clinical tool (PREDICT): scoring system to guide use of echocardiography in the management of Staphylococcus aureus bacteremia. Clin Infect Dis. 2015;61(1):18-28. https://doi.org/10.1093/cid/civ235

4. Fabijan AP, Ben Zakour NL, Ho J, Lin RCY, Iredell J, Corporation WBTTWaAB. Polyclonal Staphylococcus aureus bacteremia. Ann Intern Med. 2019;171(12):940-1. https://doi.org/10.7326/L19-0369.

5. Holland TL, Baddour LM, Bayer AS, Hoen B, Miro JM, Fowler VG. Infective endocarditis. Nat Rev Dis Primers. 2016;2:16059. https://doi.org/10.1038/ nrdp.2016.59

6. Pichon B, Hill R, Laurent F, et al. Development of a real-time quadruplex PCR assay for simultaneous detection of nuc, Panton-Valentine leucocidin (PVL), mecA and homologue mecALGA251. J Antimicrob Chemother. 2012;67(10):2338-41. https://doi.org/10.1093/jac/dks221.

7. Fosheim GE, Nicholson AC, Albrecht VS, Limbago BM. Multiplex real-time PCR assay for detection of methicillin-resistant Staphylococcus aureus and associated toxin genes. J Clin Microbiol. 2011;49(8):3071-3. https://doi. org/10.1128/JCM.00795-11.

8. Killgore GE, Holloway B, Tenover FC. A 5' nuclease PCR (TaqMan) highthroughput assay for detection of the mecA gene in staphylococci. J Clin
Microbiol. 2000;38(7):2516-9. https://doi.org/10.1128/JCM.38.7.25162519.2000.

9. Boye K, Bartels MD, Andersen IS, Møller JA, Westh H. A new multiplex PCR for easy screening of methicillin-resistant Staphylococcus aureus SCCmec types I-V. Clin Microbiol Infect. 2007;13(7):725-7. https://doi.org/10. 1111/j.1469-0691.2007.01720.x.

10. Berg AA. VI. A case of acute osteomyelitis of the femur, with general systemic Staphylococcus Aureus infection, terminating in recovery. Ann Surg. 1900:31(3):332-9. https://doi.org/10.1097/00000658-190001000-00030.

11. van Hal SJ, Jensen SO, Vaska VL, Espedido BA, Paterson DL, Gosbell IB. Predictors of mortality in Staphylococcus aureus bacteremia. Clin Microbiol Rev. 2012;25(2):362-86. https://doi.org/10.1128/CMR.05022-11.

12. Rao Q, Shang W, Hu X, Rao X. Staphylococcus aureus ST121: a globally disseminated hypervirulent clone. J Med Microbiol. 2015;64(12):1462-73. https://doi.org/10.1099/jmm.0.000185.

13. Uhlemann AC, Hafer C, Miko BA, et al. Emergence of sequence type 398 as a community- and healthcare-associated methicillin-susceptible Staphylococcus aureus in northern Manhattan. Clin Infect Dis. 2013;57(5):700-3. https://doi.org/10.1093/cid/cit375.

14. Van Eldere J, Peetermans WE, Struelens M, Deplano A, Bobbaers H. Polyclonal staphylococcal endocarditis caused by genetic variability. Clin Infect Dis. 2000;31(1):24-30. https://doi.org/10.1086/313915.

15. Hakim A, Deplano A, Maes N, Kentos A, Rossi C, Struelens MJ. Polyclonal coagulase-negative staphylococcal catheter-related bacteremia documented by molecular identification and typing. Clin Microbiol Infect. 1999;5(4):224-7. https://doi.org/10.1111/j.1469-0691.1999.tb00128.x.

16. Huang YC, Su LH, Wu TL, Lin TY. Molecular surveillance of clinical methicillin-resistant Staphylococcus aureus isolates in neonatal intensive care units. Infect Control Hosp Epidemiol. 2005;26(2):157-60. https://doi. org/10.1086/502520.

17. Votintseva AA, Miller RR, Fung R, et al. Multiple-strain colonization in nasal carriers of Staphylococcus aureus. J Clin Microbiol. 2014;52(4):1192-200. https://doi.org/10.1128/JCM.03254-13.

18. Cespedes C, Said-Salim B, Miller M, et al. The clonality of Staphylococcus aureus nasal carriage. J Infect Dis. 2005;191(3):444-52. https://doi.org/10. $1086 / 427240$.

19. Strahilevitz J, Zellermayer O, Vangel MG, Yonath H, Feinberg MS, Rubinstein E. Case clustering in infective endocarditis: the role of availability bias. Clin Microbiol Infect. 2005;11(12):955-7. https://doi.org/10.1111/j. 1469-0691.2005.01255.x.

\section{Publisher's Note}

Springer Nature remains neutral with regard to jurisdictional claims in published maps and institutional affiliations.

Ready to submit your research? Choose BMC and benefit from

- fast, convenient online submission

- thorough peer review by experienced researchers in your field

- rapid publication on acceptance

- support for research data, including large and complex data types

- gold Open Access which fosters wider collaboration and increased citations

- maximum visibility for your research: over $100 \mathrm{M}$ website views per year

At $\mathrm{BMC}$, research is always in progress.

Learn more biomedcentral.com/submissions 